\title{
PENGARUH KEPEMIMPINAN SERVANT, MOTIVASI, KOMPENSASI, DAN IKLIM ORGANISASI TERHADAP ORGANIZATIONAL CITIZENSHIP BEHAVIOR
}

\author{
Ari Tri Novita \\ Fakultas Ekonomi, Universitas Sarjanawiyata Tamansiswa \\ Daerah Istimewa Yogyakarta \\ Email korespondensi: arinovita568@gmail.com
}

\begin{abstract}
ABSTRAK
Penelitian ini bertujuan untuk mengetahui kepemimpinan melayani, motivasi, kompensasi, iklim organisasi terhadap perilaku kewargaan organisasional pada karyawan Kerupuk Ninda Rasa Kabupaten Klaten. Populasi dalam penelitian adalah 40 karyawan Kerupuk Ninda Rasa Kabupaten Klaten. Teknik pengambilan sampel dalam penelitian ini adalah accidental/haphazard sampling (pengambilan sesaat). Hasil menunjukan tidak ada pengaruh signifikan antara variabel kepemimpinan servant terhadap variabel perilaku kewargaan organisasional. Kompensasi berpengaruh terhadap perilaku kewargaan organisasional sementara iklim organisasi tidak signifikan terhadap perilaku kewargaan organisasional.
\end{abstract}

Kata kunci: kepemimpinan melayani, motivasi, kompensasi, iklim organisasi, perilaku kewargaan organisasional

\begin{abstract}
This study aims to determine the serving leadership, motivation, compensation, organizational climate on organizational citizenship behavior of the employees of Kerupuk Ninda Rasa, Klaten Regency. The population in the study were 40 employees of Kerupuk Ninda Rasa, Klaten Regency. The sampling technique utilized in this research is accidental/haphazard sampling. The results show that there is no significant effect between the servant leadership variable and the organizational citizenship behavior variable. Compensation has significant effect on organizational citizenship behavior while organizational climate is not significant on organizational citizenship behavior.
\end{abstract}

Keywords: servant leadership, motivation, compensation, organizational climate, organizational citizenship behavior

\section{PENDAHULUAN}

Kerupuk Ninda Rasa Kabupaten Klaten, kerupuk adalah sebagai pelengkap makan dan makanan ringan, kerupuk sangat sudah melebur dengan di lidah penduduk Indonesia dari semua kalangan. Banyak orang yang mengkonsumsi kerupuk. Kerupuk jenis makanan yang dapat diperoleh dimana saja tempatnya baik di pedesaan maupun perkotaan. Jenis kerupuk yang beredar sangat beragam macamnya mulai dari kerupuk udang, kerupuk ikan, rambak, kerupuk jengkol, kerupuk manggar, kerupuk terasi, rambak kedelai dan lain sebagainya.
Pabrik Kerupuk Ninda Rasa di Kabupaten Klaten Jawa Tengah merupakan salah satu perusahaan di Kabupaten Klaten yang bergerak dibidang usaha kerupuk. Lokasi pabrik kerupuk Ninda Rasa terletak di Gondangan Klaten Jawa Tengah dan didirikan Pak Seneng pada tanggal 8 Juni 2007.

SDM merupakan salah satu sumber daya yang sangat penting dari pada sumber daya lain yang dimiliki oleh perusahaan tersebut. Organizational citizenship behavior (OCB) dimunculkan supaya karyawan dapat lebih dekat dengan lingkungan kerjanya. Robbins (2006) mendefinisikan organizational 
citizenship behavior sebagai perilaku pilihan yang tidak menjadi bagian dari kewajiban formal seorang karyawan namun mendukung berfungsinya organisasi tersebut secara efektif.

\section{KAJIAN LITERATUR DAN PENGEMBANGAN HIPOTESIS}

\section{Kepemimpinan Melayani}

Sendjaya dan Sarros (2002) menjelaskan kepemimpinan melayani sebagai kepemimpinan yang melayani dengan membangun kerja sama tim dan mengembangkan aspek moral. Kepemimpinan melayani menurut Patterson (2003) merupakan kepemimpinan yang fokus terhadap pengikut, yang melayani sepenuh hati, dan peduli pada kondisi di sekitarnya.

\section{Motivasi}

Motivasi didefinisikan sebagai dorongan. Dorongan merupakan suatu gerak jiwa dan perilaku seseorang untuk memberikan dukungan kerja. Luthans (2006) menyatakan motivasi merupakan suatu proses sebagai langkah awal untuk seseorang melakukan tindakan akibat kekurangan secara fisik dan psikis, yaitu suatu dorongan yang ditunjukan untuk memenuhi tujuan tertentu.

\section{Kompensasi}

Kompensasi adalah salah satu yang berfungsi penting dalam manajemen sumber daya manusia (MSDM). Pemberian kompensasi sangat penting bagi karyawan, karena besar kecilnya kompensasi merupakan ukuran prestasi kerja karyawan, maka apabila sistem kompensasi yang diberikan organisasi agar lebih bertanggung jawab, cukup adil untuk karyawan, dan akan mendorong karyawan untuk lebih baik dalam melakukan pekerjaan atau masing-masing tugas yang diberikan oleh organisasi sesuai dengan keahlian yang di miliki. Sigit dalam Tampi (2013) menyatakan kompensasi yaitu berupa imbalan yang telah diberikan perusahaan untuk karyawan atas penghargaan yang telah diterima oleh karyawan yang bersangkutan. Lewa dan Subowo dalam Riyadi (2011) menyatakan bahwa kompensasi yang diberikan harus layak, adil, dapat diterima, memuaskan, memberi motivasi kerja, bersifat penghargaan dan sesuai dengan kebutuhan.
Lewa dan Subowo dalam Riyadi (2011) menyatakan bahwa kompensasi yang diberikan dengan adil dan layak untuk diterima, memberikan motivasi kerja, yang bersifat penghargaan dan sesuai dengan kebutuhan. dapat meningkatkan kinerja karyawan yang nantinya menguntungkan kedua belah pihak, dari karyawan sendiri maupun perusahaan.

\section{Iklim Organisasi}

Rousseau dalam Sedarmayanti (2010:75) mengatakan bahwa iklim merupakan suatu persepsi dan bersifat deskriptif. Persepsi merupakan suatu sensasi atau realisasi yang terjadi oleh seseorang. Deskripsi merupakan apa yang telah dilaporkan beberapa orang untuk mengenai sensasi tersebut. Yaitu persepsi yang secara relatif bersifat konstan yang dimiliki anggota organisasi mengenai karakteristik dan kualitas budaya organisasi. Mereka dapat membedakan antara situasi aktual (yakni budaya) dan persepsi dari itu (iklim).

\section{Organizational Citizenship Behavior}

Perilaku kewargaan organisasional didefinisikan sebagai perilaku yang telah dipilih secara bebas oleh individu dimana perilaku tersebut secara tidak langsung atau eksplisit dapat diakui oleh sistem formal dan untuk dapat meningkatkan efektivitas sebagai fungsi organisasi (Organ et al., 2006). Robbins \& Judge (2008:40) mendefinisikan OCB yaitu sebagai suatu perilaku pilihan yang tidak menjadi bagian dari kewajiban kerja karyawan, namun juga dapat mendukung berfungsinya suatu organisasi tersebut yang secara efektif.

Model penelitian ini pengaruh kepemimpinan melayani (servant), motivasi, kompensasi, dan iklim organisasi terhadap perilaku kewargaan organisasional. Keterangan:

a. Kepemimpinan Servant (X1) berpengaruh terhadap organizational citizenship behavior.

b. Motivasi (X2) berpengaruh terhadap organizational citizenship behavior.

c. Kompensasi (X3) berpengaruh terhadap organizational citizenship behavior.

d. Iklim Organisasi (X4) berpengaruh terhadap organizational citizenship behavior. 


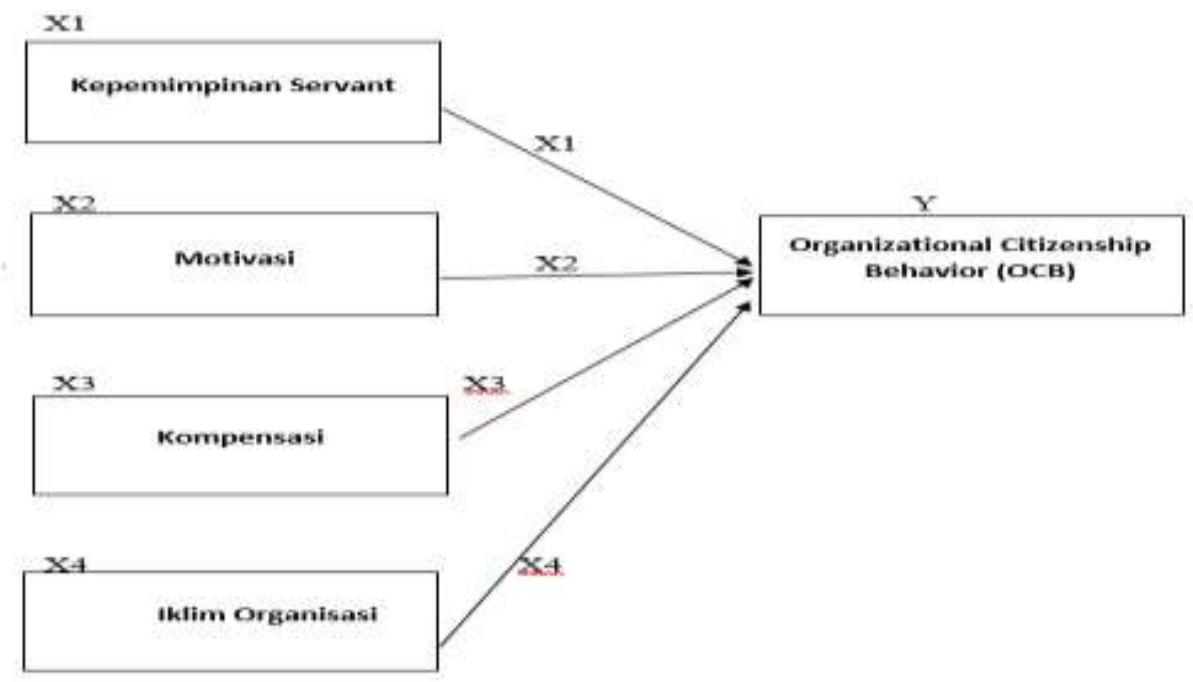

Gambar 1. Model Penelitian

\section{METODA}

\section{Jenis dan Tempat Peneitian}

Penelitian ini menggunakan penelitian jenis penelitian yang digunakan adalah deskriptif kuantitatif yang merupakan penelitian dengan menghubungkan variabel yang telah terkumpul yang berwujud angkaangka atau menggunakan alat statistik. Populasi dalam penelitian ini merupakan seluruh karyawan yang berjumlah kurang lebih 50 . Sampel dalam penelitian ini adalah 40 karyawan Pabrik Kerupuk Ninda Rasa Kabupaten Klaten tepatnya di Gondangan Klaten Jawa Tengah. Teknik pengambilan sampel yaitu accidental (pengambilan sesaat). Teknik pengumpulan data dalam penelitian ini menggunakan kuesioner, survei, skala pengukuran yang digunakan dalam penelitian ini adalah menggunakan skala Likert.

\section{Definisi Operasional}

Kepemimpinan Servant. Merupakan tingkat perilaku seorang pemimpin dengan bentuk melayani karyawan dengan tujuan untuk memberikan pemahaman dan karyawan bekerja dengan nyaman. Greenleaf (1977) dalam Spears (2010) menyatakan bahwa tingkat perilaku ini diukur menggunakan skala dengan aspek: Organizational Stewarship, Wisdom, Service, Humility, Vision, Persuasive Mapping dan Emotional Calling.

Motivasi. Menurut Siagian (2007:285) dalam Brahmasari dan Suprayetno (2008), menyatakan motivasi kerja merupakan segala sesuatu yang telah menjadi pendorong tingkah laku yang menuntut orang untuk memenuhi kebutuhannya.

Kompensasi. Samsudin (2006: 187) kompensasi mengandung arti dari pada upah atau gaji. Upah atau gaji yang menekankan pada balas jasa yang bersifat finansial, sedangkan kompensasi mencakup balas jasa finansial maupun non-finansial. Indikatorindikator kompensasi menurut Samsudin (2006: 187) terdapat dua indikator untuk mengukur variabel kompensasi.

Iklim organisasi. Iklim organisasi adalah kualitas lingkungan internal dalam organisasi yang memiliki karakteristik, sehingga berbeda dengan organisasi lainnya. Digambarkan melalui persepsi para anggota organisasi terhadap lingkungan kerja mengenai yang terjadi di sekitaran organisasi, yang mempengaruhi sikap dan perilaku anggota organisasi. Koys dan Decotiis (1991) mendefinisikan iklim organisasi sebagai persepsi bersama anggota organisasi terhadap lingkungan kerja mengenai apa yang diberikan oleh organisasi atau yang ada secara ruti di sekitar lingkungan yang internal organisasi, yang mempengaruhi skap dan perilaku anggota organisasi selanjutnya.

Organizational Citizenship Behavior. Organizational Citizenship Behavior (OCB) merupakan suatu perilaku yang mampu diperankan oleh karyawan, dimana karyawan dapat bekerja dan tidak ada batas pada deskripsi tugas semata (Golparvar dan Javadian, 2012:1). 
HASIL

Uji Normalitas Data. Dari hasil uji normalitas Kolmogorov Smirnov diatas diketahui nilai Kolmogorov-Smirnov Z 0,820 dan nilai Asymp. Sig. (2-tailed) sebesar 0,513 yang diperoleh model regresi lebih dari signifikan 0,05 berarti distribusi data dalam penelitian ini normal.

Tabel 1

Hasil Uji Normalitas

One-Sample Kolmogorov-Smirnov Test

\begin{tabular}{llc}
\hline & & Unstandardized Residual \\
\hline $\mathrm{N}$ & & 40 \\
\hline Normal Parameters $^{\mathrm{a}}$ & Mean & .0000000 \\
& Std. Deviation & 5.79499036 \\
Most Extreme Differences & & .130 \\
& Absolute & .084 \\
& Positive & -.130 \\
Kolmogorov-Smirnov Z & Negative & .820 \\
Asymp. Sig. (2-tailed) & & .513 \\
\hline
\end{tabular}

Sumber: Data diolah

\section{Uji Multikolinieritas}

Berdasarkan Tabel 2, dapat diketahui nilai Variance Inflation Factor (VIF) ketiga variabel X1 (kepemimpinan servant) $=1,133$,
X2 $($ motivasi $)=1,095, \mathrm{X} 3$ (kompensasi) 1,210 dan X4 (iklim organisasi) $=1,163$ dibawah 10 maka tidak terjadi multikolonieritas.

Tabel 2.

Uji Multikolinieritas

\begin{tabular}{cccc}
\hline Variabel & Tolerance & VIF & Hasil \\
\hline Kepemimpinan Servant & 0.883 & 1.133 & Non Multikolineritas \\
Motivasi & 0.913 & 1.095 & Non Multikolineritas \\
Kompensasi & 0.827 & 1.210 & Non Multikolineritas \\
Iklim Organisasi & 0.860 & 1.163 & Non Multikolineritas \\
\hline
\end{tabular}

Sumber: Data diolah

a. Dependent Variable: OCB

\section{Uji Heteroskedastisitas}

Hasil uji Glejser menunjukkan bahwa tidak terdapat heteroskedastisitas pada model persamaan regresi tersebut. Hal tersebut dilihat dari adanya variabel independen yang memiliki signifikansi $0,754>0,05,0,701>0,05,0,574>$ 0,05 dan 0,549>0,05. Dengan demikian dapat disimpulkan bahwa data persamaan model regresi dengan menggunakan uji Glejser tidak ada yang mempunyai permasalahan heteroskedastisitas atau disebut tidak terjadi heteroskedastisitas. 
Tabel 3.

Hasil Uji Heteroskedastisitas Coefficients $^{\text {a }}$

\begin{tabular}{|c|c|c|c|c|c|}
\hline \multirow[b]{2}{*}{ Model } & \multicolumn{2}{|c|}{$\begin{array}{l}\text { Unstandardized } \\
\text { Coefficients }\end{array}$} & \multirow{2}{*}{$\begin{array}{c}\text { Standardized } \\
\text { Coefficients } \\
\text { Beta }\end{array}$} & \multirow[b]{2}{*}{$\mathbf{T}$} & \multirow[b]{2}{*}{ Sig. } \\
\hline & B & Std. Error & & & \\
\hline 1 (Constant) & 1.298 & 7.689 & & .169 & .867 \\
\hline Kepemimpinan Servant & -.041 & .131 & -.055 & -.316 & .754 \\
\hline Motivasi & -.066 & .170 & -.067 & -.387 & .701 \\
\hline Kompensasi & .090 & .158 & .103 & .568 & .574 \\
\hline Iklim Organisasi & .149 & .157 & .169 & .950 & .549 \\
\hline
\end{tabular}

a. Dependent Variable: Abs_RES

Sumber: Data primer diolah, 2019

Tabel 4.

Hasil Analisis Regresi Linier Berganda Coefficients $^{\mathrm{a}}$

\begin{tabular}{lccccc}
\multicolumn{1}{c}{ Model } & \multicolumn{2}{c}{$\begin{array}{c}\text { Unstandardized } \\
\text { Coefficients }\end{array}$} & $\begin{array}{c}\text { Standardized } \\
\text { Coefficients }\end{array}$ & \\
& B & Std. Error & Beta & T & Sig. \\
\hline 1 (Constant) & -.036 & 13.566 & & -.003 & .998 \\
Kepemimpinan Servant & -.005 & .232 & -.003 & -.019 & .985 \\
Motivasi & .460 & .300 & .237 & 1.536 & .133 \\
Kompensasi & .647 & .278 & .377 & 2.323 & .026 \\
Iklim Organisasi & .007 & .277 & .004 & .026 & .979 \\
\hline
\end{tabular}

a. Dependent Variable: OCB

Sumber: Data primer diolah, 2019

Berdasarkan tabel 4 dijelaskan sebagai berikut: Ada pengaruh negatif tidak signifikan antara variabel kepemimpinan servant terhadap organizational citizenship behavior dengan nilai signifikansi 0,985 dimana nilai ini diatas 0,05 . Ada pengaruh negatif tidak signifikan antara variabel motivasi terhadap organizational citizenship behavior dengan nilai signifikansi 0,133 dimana nilai ini diatas 0,05 . Ada pengaruh positif signifikan antara variabel kompensasi terhadap organizational citizenship behavior dengan nilai signifikansi 0,026 dimana nilai ini di bawah 0,05. Ada pengaruh negatif tidak signifikan antara variabel kompensasi terhadap organizational citizenship behavior dengan nilai signifikansi 0,979 dimana nilai ini di atas 0,05 .

\section{Uji Koefisien Determinasi $\left(\mathbf{R}^{\mathbf{2}}\right)$}

Dari hasil perhitungan diketahui nilai $\mathrm{R}$ square sebesar 0,238 . Nilai ini menunjukkan bahwa variabel kepemimpinan servant, motivasi, kompensasi, iklim organisasi memberi sumbangan sebesar $23,8 \%$ dalam mempengaruhi organizational citizenship behavior. Adapun yang 0,762\% dipengaruhi oleh variabel-variabel lain di luar model penelitian ini.

\section{PEMBAHASAN}

\section{Pengaruh Kepemimpinan Melayani terhadap Organizational Citizenship Behavior Kerupuk Ninda Rasa Klaten}

Berdasarkan hasil uji hipotesis, penelitian ini menunjukkan bahwa nilai signifikansi kepemimpinan servant terhadap organizational citizenship behavior adalah $0,985>0,05$ artinya kepemimpinan servant tidak berpengaruh signifikan terhadap organizational citizenship behavior. Hal ini tergolong kepemimpinan servant kurang 
mempengaruhi organizational citizenship behavior.

\section{Pengaruh Motivasi Terhadap Organizational Citizenship Behavior Kerupuk Ninda Rasa Klaten}

Berdasarkan hasil uji hipotesis, penelitian ini menunjukkan bahwa nilai signifikansi motivasi terhadap organizational citizenship behavior adalah 0,133>0,05 artinya motivasi tidak berpengaruh signifikan terhadap organizational citizenship behavior $\mathrm{Hal}$ ini tergolong motivasi kurang mempengaruhi organizational citizenship behavior.

\section{Pengaruh Kompensasi Terhadap Organizational Citizenship Behavior Kerupuk Ninda Rasa Klaten}

Berdasarkan hasil uji hipotesis, penelitian ini menunjukkan bahwa nilai signifikansi kompensasi terhadap organizational citizenship behavior adalah $0,026>0,05$ artinya kompensasi berpengaruh positif signifikan terhadap organizational citizenship behavior. Hal ini tergolong kompensasi mempengaruhi organizational citizenship behavior.

\section{Pengaruh Iklim Organinisasi Terhadap Organizational Citizenship Behavior Kerupuk Ninda Rasa Klaten}

Berdasarkan hasil uji hipotesis, penelitian ini menunjukkan bahwa nilai signifikansi iklim organisasi terhadap organizational zzzcitizenship behavior adalah $0,979>0,05$ artinya iklim organisasi tidak berpengaruh signifikan terhadap organizational citizenship behavior. Hal ini tergolong iklim organisasi kurang mempengaruhi organizational citizenship behavior.

\section{SIMPULAN, KETERBATASAN, DAN SARAN}

\section{Kesimpulan}

Dari penelitian diatas dapat ditarik kesimpulan beberapa hal. Pertama, kepemimpinan servant mempunyai pengaruh negatif, tidak signifikan antara variabel kepemimpinan servant terhadap organizational citizenship behavior kerupuk Ninda Rasa Klaten. Dengan nilai signifikansi 0,985 dimana nilai ini diatas 0,05 . Dengan ini hipotensis H1 ditolak.

Kedua, motivasi mempunyai pengaruh negatif, tidak signifikan antara variabel kompensasi terhadap organizational citizenship behavior kerupuk Ninda Rasa Klaten. Dengan nilai signifikansi 0,133 dimana nilai ini diatas 0,05 . Dengan ini hipotesis H2 ditolak.

Ketiga, kompensasi mempunyai pengaruh positif, signifikan antara variabel kompensasi terhadap organizational citizenship behavior kerupuk Ninda Rasa Klaten. Dengan nilai signifikansi 0,026 dimana nilai ini di atas 0,05 . Dengan ini hipotensis H3 diterima.

Keempat, iklim organisasi mempunyai pengaruh negatif, tidak signifikan antara variabel iklim organisasi terhadap organizational citizenship behavior kerupuk Ninda Rasa Klaten. Dengan nilai signifikansi 0,979 dimana nilai ini diatas 0,05 . Dengan ini hipotensis H4 ditolak.

\section{Keterbatasan Penelitian}

Responden dalam penelitian ini terbatas hanya pada karyawan di Kerupuk Ninda Ras. Data yang dikumpulkan dan dianalisis menggunakan metode kuesioner, sehingga memungkinkan terjadinya pengisian kuesioner responden yang tidak bersungguh-sungguh dan dapat menimbulkan hasil yang menyesatkan.

\section{Saran}

Berdasarkan kesimpulan diatas, maka saran yang dapat diberikan sebagai bahan masukan. Dengan keterbatasan dalam penelitian ini, diharapkan peneliti yang akan datang dapat mengembangkan lebih lanjut variabel-variabel lain selain, kepemimpinan servant, motivasi, iklim organisasi dan organizational citizenship behavior dalam penelitiannya.

Kompensasi berpengaruh positif signifikan terhadap organizational citizenship 
behavior. Pemberian kompensasi sangat penting bagi karyawan, karena besar kecilnya kompensasi merupakan ukuran prestasi kerja karyawan, maka apabila sistem kompensasi yang diberikan organisasi cukup adil untuk karyawan, perusahaan harus lebih meningkatkan bagaimana program kerjanya. Penelitian ini dapat menjadi acuan bagi perusahaan dalam meningkatkan kepuasan

\section{REFERENSI}

Brahmasari, I.A. (2008) 'Pengaruh Variabel Budaya Organisasi, Komitmen dan Kepuasan

Kerja Pegawai Terhadap Organizational Citizenship Behavior Pegawai" Jurnal

Garay, Hannah Dara Vanzuela, 2006. Kinerja Extra-Role dan Kebijakan Kompensasi. SINERGI, Kajian Bisnis Dan Manajemen, 8(1) : 33-42.

Hardaningtyas, Dwi, 2005, Pengaruh Tingkat Kecerdasan Emosi dan Sikap pada Budaya Organisasi terhadap Organizational Citizenship Behavior (OCB) Pegawai PT. (Persero) Pelabuhan Indonesia III, Program Paskasarjana Universitas Airlangga, Surabaya, (http://www.damandiri.or.id/detail.php ?id=334), diakses 16 Maret 2015.

Lieke. 2008. Jurnal Pengaruh Kompensasi dan Motivasi Kerja terhadap Komitmen Organisasi.

Luthans, F. 2006. Perilaku Organisasi. Edisi Sepuluh. Yogyakarta: Andi Offset.

Organ, D.W., et.al., 2006. Organizational Citizenship Behavior. Its Nature, Antecendents, and Consequences. California: SagePublications, Inc. kerja dan penelitian ini dapat membantu menemukan masalah yang ada di dalam perusahaan sehingga menjadi bahan pertimbangan bagi perusahaan. Penelitian selanjutnya dapat menggunakan metode wawancara sehingga mendapatkan hasil yang lebih baik dibandingkan dengn menggunakan metode kuesioner.

Riyadi, Slamet. 2011. Pengaruh Kompensasi Finansial, Gaya Kepemimpinan, dan Motivasi Kerja terhadap Kinerja Karyawan pada Perusahaan Manufaktur di Jawa Timur. Jurnal Manajemen dan Kewirausahaan, 13(1): 40-45.

Robins dan Judge. 2008. Perilaku Organisasi. Jakarta: Salemba Empat.

Samsudin, Sadili, 2006, Manajemen Sumber Daya Manusia. Bandung: Penerbit CV Pustaka Setia.

Sendjaya, S. dan Sarros, J. C. 2002. Servant leadership: Its Origin, Development and Application in Organizations. Journal of Leadership and Organization Studies.

Sendjaya, S., Sarros, J.C., \& Santora, J.C. (2008). Defining and Measuring Servant Leadership Behavior in Organizations. Journal of Management Studies, 45(2), 402-424

Soentoro, D. P. 2013. Pengaruh Motivasi Kerja, Kepemimpinan, Lingkungan Kerja terhadap Organizational Citizenship Behavior ean Kepuasan Kerja di PT Sucofindo Surabaya.

Tampi, Gina Sheelsia. 2013. Kepemimpinan dan Kompensasi pengaruhnya terhadap Kinerja Karyawan dan dampaknya terhadap Organizational Citizenship Behavior (OCB). Jurnal EMBA, 1(3): 921-929. 